\title{
Identification of a Sex-Specific Quantitative Trait Locus Mediating Nonopioid Stress-Induced Analgesia in Female Mice
}

\author{
Jeffrey S. Mogil ${ }^{1,2}$, Susan P. Richards, ${ }^{1}$ Laurie A. O'Toole, ${ }^{1}$ Melinda L. Helms, ${ }^{1}$ Steve R. Mitchell, ${ }^{1}$ \\ Benjamin Kest, ${ }^{3}$ and John K. Belknap ${ }^{1}$ \\ ${ }^{1}$ Department of Behavioral Neuroscience and Veterans Affairs Medical Center, Oregon Health Sciences University, \\ Portland, Oregon 97201, '2Department of Psychology, University of Illinois at Urbana-Champaign, Champaign, Illinois \\ 61820, and ${ }^{3}$ Department of Psychology, College of Staten Island/City University of New York, Staten Island, \\ New York 10314
}

It is increasingly appreciated that the sexes differ in their perception of noxious stimuli and in their responsivity to exogenous and endogenous analgesic manipulations. We previously reported the existence of qualitative sex differences in the neurochemical mediation of nonopioid (i.e., naloxone-insensitive) stress-induced analgesia (SIA) produced by forced swims and suggested that female mice possess a sex-specific SIA mechanism. This femalespecific system is now known to be estrogen-dependent, to be ontogenetically organized, and to vary with reproductive status; however, its neurochemical identity remains obscure. In an attempt to identify candidate genes underlying SIA in both sexes, we performed a two-phase quantitative trait locus (QTL) mapping experiment using the BXD/Ty recombinant inbred (RI) set derived from DBA/2J (D2) and C57BL/6J (B6) inbred mouse strains and $(\mathrm{B} 6 \mathrm{xD2}) \mathrm{F}_{2}$ hybrid mice derived from these same progenitors. All mice were subjected to $3 \mathrm{~min}$ forced swims in $15^{\circ} \mathrm{C}$ water; nociceptive sensitivity on the $54^{\circ} \mathrm{C}$ hot-plate assay was assessed immediately before and $2 \mathrm{~min}$ after cessation of the swim. We report the localization of a QTL statistically associated with SIA magnitude $[p=0.00000012$; logarithm of the odds $(\mathrm{LOD})=6.1]$ in female mice only. This female-specific QTL, which we name Fsia1, is located on chromosome 8 at $52-84 \mathrm{cM}$ from the centromere and accounts for $17-26 \%$ of the overall trait variance in this sex. The present data provide further evidence of the existence of a female-specific SIA mechanism and highlight the important role of both genetic background and gender in the inhibition of pain.

Key words: sex differences; genetics; antinociception; stressinduced analgesia; gene mapping; quantitative trait locus; nonopioid; pain
It is well known that the CNS contains circuitry that evolved to inhibit ascending nociceptive signals. These endogenous pain inhibition mechanisms can be activated by direct electrical stimulation or pharmacologically, but they evolved to be activated by exposure to environmental stressors, a phenomenon known as stress-induced analgesia (SIA) (Kelly, 1986). Multiple SIA systems are known to exist; in the simplest dissociation they can be divided into opioid or nonopioid forms, on the basis of their sensitivity to antagonism by the prototypic opioid receptor blockers naloxone or naltrexone (Lewis et al., 1980; Watkins and Mayer, 1982; Terman et al., 1984).

It is possible to observe opioid or nonopioid SIA after the application of the same laboratory stressor by altering stress severity parameters. For instance, in Swiss-Webster mice, swims of longer duration and/or colder temperature produce increasingly nonopioid SIA, that is, SIA increasingly refractory to naloxone/naltrexone antagonism (Marek et al., 1992; Mogil et al., 1993, 1996b; but see Tierney et al., 1991).

Much is known regarding the neurochemical and anatomical details of endogenous opioid pain inhibition mechanisms (Basbaum and Fields, 1984). Opioid peptide neurotransmitters are

Received May 29, 1997; revised July 29, 1997; accepted July 30, 1997.

This research was supported by a National Research Service Award Fellowship from National Institutes of Health to J.S.M. and a Veterans Affairs Merit Review Program to J.K.B. We thank Dr. Nicholas Grahame for his helpful comments.

Correspondence should be addressed to Dr. Jeffrey S. Mogil, Department of Psychology, University of Illinois at Urbana-Champaign, 603 E. Daniel Street, Champaign, IL 61820.

Copyright (C) 1997 Society for Neuroscience $0270-6474 / 97 / 177995-08 \$ 05.00 / 0$ released and act on opioid receptors in the periaqueductal gray and the spinal cord, and serotonin and various peptide neurotransmitters participate as well (Basbaum and Fields, 1984; Mayer and Frenk, 1988). Some details regarding the anatomy of nonopioid pain inhibitory systems have been determined in studies of stimulation-produced analgesia; for example, naloxone-resistant analgesia can be produced by stimulating the dorsal rather than ventral periaqueductal gray (Cannon et al., 1982). In contrast, the neurochemistry of nonopioid mechanisms, as implied by their name, remains largely obscure. There exist a number of reports describing the selective attenuation of nonopioid SIA-variously supporting the involvement of $\mathrm{H}_{2}$ histamine receptors (Gogas et al., 1986; Gogas and Hough, 1989), serotonin 5-HT 1A $_{\text {(Rodgers }}$ and Shepherd, 1989; Kavaliers and Colwell, 1991), 5-HT 2 , and 5- $\mathrm{HT}_{3}$ receptors (Rodgers et al., 1990), GABA $\mathrm{A}$ receptors (Rodgers and Randall, 1987; Kavaliers, 1988), $\alpha_{2}$-adrenergic receptors (Bodnar et al., 1983; Coderre and Rollman, 1984; Chance, 1986; Watkins et al., 1992), NMDA receptors (Marek et al., 1991; Marek et al., 1992; Ben-Eliyahu et al., 1993), or the parallel activation of multiple spinal opioid receptor types (Watkins et al., 1992) - but contradictory data abound, and no consensus has emerged.

We further complicated this field several years ago when in an attempt to replicate our study showing that 3 min swims in $15^{\circ} \mathrm{C}$ water produce nonopioid SIA that is attenuated by low doses $(0.075 \mathrm{mg} / \mathrm{kg}$, i.p.) of the NMDA antagonist dizocilpine (MK801 ), we observed that female mice were wholly insensitive to such antagonism (Mogil et al., 1993). Nonetheless, females exhib- 
ited equipotent SIA from the swims compared with males, implying the existence of a female-specific, nonopioid, nonNMDAergic SIA mechanism. We (Sternberg et al., 1994, 1996) and others (Kavaliers and Galea, 1996) have replicated and extended this finding (see Discussion), but the neurochemical nature of the female-specific system remains entirely unknown.

In addition to the role of sex, we and others have amassed considerable evidence pointing to the important role of genotype or genetic background in the modulation of exogenous and endogenous pain inhibition (for review, see Belknap and O'Toole, 1991; Mogil et al., 1996c). The recently developed techniques of molecular gene mapping have only now begun to be applied to pain-related traits, and quantitative trait loci (QTLs) have been identified for morphine analgesia (Belknap et al., 1995; Mogil et al., 1995) and basal nociceptive sensitivity (Mogil et al., 1997). Such approaches are very useful for generating novel hypotheses regarding physiological mediation of a trait, and we reasoned that a QTL mapping study of nonopioid SIA might serve to provide confirmatory and/or heuristic information regarding the neurochemical identity of this puzzling phenomenon. Furthermore, this experiment might be viewed as a direct attempt to identify the true nature of the female-specific SIA system without having to resort to the administration of numerous, arbitrarily chosen antagonists. In pilot data collected to these ends, we determined that 3 min swims in $15^{\circ} \mathrm{C}$ water produce nonopioid, non-NMDAergic SIA in females of both the DBA/2J (D2) and C57BL/6J (B6) strains (Mogil and Belknap, 1997). These strains were chosen for this study because of their progenitor status with respect to the $\mathrm{BXD} / \mathrm{Ty}$ recombinant inbred (RI) strain set available at the Veterans Affairs Animal Research Facility. Like the SwissWebster mice used in the seminal studies, male B6 mice also displayed dizocilpine-sensitive nonopioid SIA. To our surprise, male D2 mice exhibited naloxone-reversible, opioid SIA after these swim stress parameters, indicating that the selective activation of neurochemically distinct SIA mechanisms is determined by both sex and genotype (Mogil and Belknap, 1997). The present study adds important evidence to this contention, because we have identified two female-specific QTLs that account for variability in nonopioid SIA magnitude between D2 and B6 mice.

Some of these data have been published previously (Mogil et al., 1997).

\section{MATERIALS AND METHODS}

Subjects. Mice used in this experiment were the same as those used in a previous QTL mapping experiment that considered basal sensitivity to hot-plate nociception (Mogil et al., 1997). Subjects were naïve, adult (8to 12-week-old) mice of both sexes of the following populations: B6, D2, $(\mathrm{B} 6 \mathrm{xD} 2) \mathrm{F}_{1}$ hybrids (both reciprocals), (B6xD2)F $\mathrm{F}_{2}$ hybrids (all reciprocals), and $24 \mathrm{BXD} / \mathrm{Ty}$ (BXD) RI strains (BXD-1 through BXD-32; strains $\mathrm{BXD}-3,-4,-7,-10,-17,-20$, and -26 are no longer extant; the BXD-24 strain was unavailable). All mice were bred at the Veterans Affairs Animal Research Facility (Portland, OR) from breeding stock originally obtained from The Jackson Laboratory (Bar Harbor, ME) no more than three generations earlier. Mice were weaned at 22-25 d and housed with their same-sex littermates, two to five mice per cage, in a temperature-controlled $\left(22^{\circ} \mathrm{C}\right)$ environment. Subjects were maintained on a $12 \mathrm{hr}$ light/dark cycle (lights on at 6 A.M.), and all testing proceeded near mid-photophase to reduce circadian effects on pain sensitivity (Kavaliers and Hirst, 1983).

Algesiometric testing. Details of the hot-plate assay used have been described previously (Mogil et al., 1996a, 1997). Briefly, mice were removed from their home cages and placed on an aluminum surface maintained at $54.0 \pm 0.2^{\circ} \mathrm{C}$ (Thermolyne Dri-Bath, Thermolyne, Dubuque, IA). Locomotion was limited by $15-\mathrm{cm}$-high Plexiglas walls to a $10 \times$ $10 \mathrm{~cm}$ area. Latency to respond to the heat stimulus with a behavior indicative of nociception (sustained hindpaw lift, hindpaw lick, or hind- paw shake/flutter) was measured to the nearest $0.1 \mathrm{sec}$ with a stopwatch by an observer blind to genotype. In the absence of any of these responses after $60 \mathrm{sec}$, mice were removed from the plate and assigned a cut-off latency of 60 . Mice were tested for nociceptive sensitivity on the $54^{\circ} \mathrm{C}$ hot-plate test immediately before and 2 min after forced swims.

Swim SIA. SIA was produced by exposing mice to $3 \mathrm{~min}$ forced swims in $15^{\circ} \mathrm{C}\left( \pm 1^{\circ} \mathrm{C}\right)$ water, as we have previously described (Marek et al., 1992; Mogil et al., 1993, 1996b; Mogil and Belknap, 1997). An experimenter maintained the water at the desired temperature by constant monitoring and the periodic addition of ice as needed. Mice were placed in a cylindrical plastic container $28 \mathrm{~cm}$ in diameter and $44 \mathrm{~cm}$ in height. The water level ranged from 30 to $35 \mathrm{~cm}$ high, so that escape was impossible. On completion of the $3 \mathrm{~min}$ swim, mice were towel-dried and placed in a paper towel-lined enclosure for $2 \mathrm{~min}$ to dry before being retested for nociceptive sensitivity on the hot plate.

SIA was expressed as the percentage of the maximum possible effect (\% MPE), as calculated by the following formula:

$$
\% \mathrm{MPE}=\frac{(\text { post-swim latency }- \text { baseline latency })}{(\text { cut-off latency }- \text { baseline latency })} \times 100
$$

The use of $\% \mathrm{MPE}$ takes into account the cut-off latency and individual baseline latencies, so that these will not bias the quantification of analgesia. This transformation, however, has been criticized for imposing an arbitrary ceiling that may lead to distortions (Carmody, 1995). With this potential problem in mind, we also considered other possible indices of analgesic magnitude, including the raw change in hot-plate latency, the uncorrected percentage latency change, and the change in the nociception index (1/latency), as suggested by Carmody (1995). We found that these alternative indices were very highly correlated with each other $(r=$ $0.80-0.91)$; we chose, therefore, to present and analyze \%MPE data herein. In fact, ANOVAs were performed on all of these indices (not shown), and results were qualitatively the same in every case.

QTL mapping. A two-phase mapping strategy was used, as described in detail previously (Belknap et al., 1995). In the first phase, BXD RI strain distributions were collected by obtaining hot-plate latency means for each BXD strain $(n=6-11$ per sex per strain, except for BXD-9 and BXD-22, in which only four males and three females, respectively, were available for testing). The hot-plate latency distributions were used to screen a database of strain distribution patterns of the allelic form (D2-derived or B6-derived) of $>1200$ polymorphic microsatellite DNA markers, naturally occurring stretches of DNA often consisting of a dinucleotide repeat (e.g., [CA $]_{n}$ ), of known chromosomal location (Manly, 1993). Correlation coefficients were calculated for each comparison between the phenotype (mean \%MPE) and genotype ( 0 if the strain exhibits a fixed homozygous B6 allele at that marker; 1 if the strain exhibits a fixed homozygous D2 allele) of the RI strain. Genomic regions found to be statistically associated with hot-plate latency at $p<0.01$ were subjected to confirmation testing in the second phase, using mice of a $(\mathrm{B} 6 \mathrm{xD} 2) \mathrm{F}_{2}$ intercross. The choice to use an $\alpha$ level of 0.01 in our preliminary genome screen was arbitrary; we wished to strike a balance between minimizing Type I errors (false positives), which calls for more stringent $\alpha$ levels, and minimizing Type II errors (false negatives), which calls for less stringent $\alpha$ levels. At the 0.01 level, our computer simulations show that approximately half of all provisionally identified QTLs are likely to be correct positives for the BXD data alone (Belknap et al., 1996).

In the second phase, $293(\mathrm{~B} 6 \mathrm{xD} 2) \mathrm{F}_{2}$ hybrid mice were bred and tested exactly as were the BXD RI mice used previously. Three or more new microsatellite markers known to be polymorphic in the D2 and B6 strains (Dietrich et al., 1996) were chosen to bracket each RI-implicated region, and some $\mathrm{F}_{2}$ hybrids were genotyped at each marker (see below). Each $\mathrm{F}_{2}$ animal is genetically unique and represents a new recombination of progenitor alleles. Because unlimited numbers of $\mathrm{F}_{2}$ mice can be bred and tested, this approach transcends the statistical power limitations inherent in the initial BXD RI screening phase. The testing of $\mathrm{F}_{2}$ mice is associated with two disadvantages, however: (1) phenotype measurement will be less accurate because the phenotypic value is a single datum as opposed to a strain mean, and (2) half of all $\mathrm{F}_{2}$ mice will have inherited heterozygous alleles at relevant loci, rendering them less informative. This latter limitation can be mitigated somewhat by using selective genotyping, in which only extreme responding $\mathrm{F}_{2}$ mice (both high and low tails of the distribution) are genotyped (Lander and Botstein, 1989). We used a selective genotyping paradigm in which 140 (79 male, 61 female) of 293 phenotyped mice were genotyped. This strategy reduces 
Table 1. Raw data from all genetic populations ${ }^{a}$

\begin{tabular}{|c|c|c|c|c|c|c|c|c|c|}
\hline \multirow[b]{2}{*}{ Strain } & \multicolumn{3}{|c|}{ All mice } & \multicolumn{3}{|c|}{ Female mice } & \multicolumn{3}{|c|}{ Male mice } \\
\hline & $n$ & BL & PS & $n$ & $\mathrm{BL}$ & PS & $n$ & $\mathrm{BL}$ & PS \\
\hline B6 & 13 & $19.1 \pm 1.2$ & $46.5 \pm 4.3$ & 7 & $20.5 \pm 1.4$ & $46.7 \pm 5.0$ & 6 & $17.5 \pm 1.9$ & $46.2 \pm 7.7$ \\
\hline $\mathrm{D} 2$ & 17 & $24.3 \pm 1.6$ & $42.5 \pm 3.9$ & 8 & $22.2 \pm 2.4$ & $39.1 \pm 4.5$ & 9 & $26.1 \pm 2.0$ & $45.6 \pm 6.3$ \\
\hline$(\mathrm{B} 6 \mathrm{xD} 2) \mathrm{F}_{1}$ & 26 & $18.0 \pm 0.9$ & $38.5 \pm 3.6$ & 8 & $18.8 \pm 2.2$ & $37.5 \pm 6.7$ & 18 & $17.7 \pm 0.8$ & $39.0 \pm 4.4$ \\
\hline BXD-1 & 14 & $22.6 \pm 0.9$ & $58.2 \pm 1.2$ & 7 & $21.4 \pm 0.6$ & $58.1 \pm 1.9$ & 7 & $23.7 \pm 1.7$ & $58.3 \pm 1.7$ \\
\hline BXD-2 & 15 & $19.4 \pm 1.6$ & $32.5 \pm 3.8$ & 7 & $20.0 \pm 2.4$ & $29.6 \pm 3.2$ & 8 & $18.9 \pm 2.1$ & $35.1 \pm 6.6$ \\
\hline BXD-5 & 15 & $18.3 \pm 1.7$ & $48.2 \pm 4.8$ & 8 & $17.1 \pm 2.3$ & $51.6 \pm 5.9$ & 7 & $19.8 \pm 2.5$ & $44.2 \pm 8.0$ \\
\hline BXD-6 & 18 & $19.8 \pm 1.8$ & $50.6 \pm 3.0$ & 9 & $19.9 \pm 2.9$ & $51.3 \pm 4.4$ & 9 & $19.7 \pm 2.2$ & $49.9 \pm 4.4$ \\
\hline BXD-8 & 17 & $28.6 \pm 2.1$ & $52.1 \pm 3.5$ & 10 & $27.3 \pm 2.8$ & $54.2 \pm 3.3$ & 7 & $30.5 \pm 3.2$ & $49.1 \pm 7.2$ \\
\hline BXD-9 & 12 & $19.8 \pm 2.1$ & $55.5 \pm 3.1$ & 8 & $16.3 \pm 2.2$ & $53.2 \pm 4.4$ & 4 & $26.6 \pm 1.9$ & $60 \pm 0$ \\
\hline BXD-11 & 16 & $18.1 \pm 1.7$ & $52.5 \pm 3.6$ & 9 & $14.9 \pm 1.7$ & $54.5 \pm 3.8$ & 7 & $22.1 \pm 2.6$ & $49.8 \pm 7.0$ \\
\hline BXD-12 & 14 & $24.5 \pm 1.7$ & $55.1 \pm 2.1$ & 7 & $26.0 \pm 2.8$ & $55.4 \pm 3.3$ & 7 & $23.0 \pm 2.1$ & $54.7 \pm 2.7$ \\
\hline BXD-13 & 14 & $23.9 \pm 2.3$ & $60 \pm 0$ & 7 & $21.3 \pm 2.2$ & $60 \pm 0$ & 7 & $26.6 \pm 4.0$ & $60 \pm 0$ \\
\hline BXD-14 & 13 & $24.6 \pm 2.2$ & $35.8 \pm 4.6$ & 6 & $18.7 \pm 1.2$ & $30.0 \pm 7.5$ & 7 & $29.7 \pm 2.8$ & $40.9 \pm 5.5$ \\
\hline BXD-15 & 19 & $18.3 \pm 1.6$ & $43.9 \pm 3.6$ & 10 & $16.5 \pm 2.7$ & $39.4 \pm 5.7$ & 9 & $20.3 \pm 1.6$ & $48.8 \pm 3.8$ \\
\hline BXD-16 & 15 & $15.1 \pm 1.5$ & $49.6 \pm 3.6$ & 8 & $15.9 \pm 0.6$ & $50.2 \pm 5.1$ & 7 & $14.1 \pm 3.2$ & $48.8 \pm 5.5$ \\
\hline BXD-18 & 18 & $25.9 \pm 1.7$ & $51.5 \pm 3.0$ & 7 & $23.6 \pm 2.7$ & $47.7 \pm 6.2$ & 11 & $27.4 \pm 2.1$ & $53.9 \pm 3.1$ \\
\hline BXD-19 & 17 & $16.1 \pm 1.5$ & $33.1 \pm 3.1$ & 9 & $15.2 \pm 2.3$ & $34.0 \pm 4.4$ & 8 & $17.0 \pm 1.9$ & $32.1 \pm 4.5$ \\
\hline BXD-21 & 14 & $20.9 \pm 1.5$ & $56.4 \pm 3.2$ & 7 & $20.7 \pm 2.7$ & $60 \pm 0$ & 7 & $21.0 \pm 1.4$ & $52.7 \pm 6.3$ \\
\hline BXD-22 & 9 & $24.6 \pm 3.2$ & $44.2 \pm 6.5$ & 3 & $17.3 \pm 5.5$ & $31.7 \pm 14.2$ & 6 & $28.2 \pm 3.2$ & $50.5 \pm 6.0$ \\
\hline BXD-23 & 16 & $15.9 \pm 2.1$ & $37.0 \pm 4.0$ & 8 & $13.5 \pm 2.1$ & $31.5 \pm 5.5$ & 8 & $18.2 \pm 3.5$ & $42.6 \pm 5.5$ \\
\hline BXD-25 & 18 & $24.2 \pm 2.0$ & $54.9 \pm 2.6$ & 8 & $19.5 \pm 2.1$ & $57.1 \pm 2.9$ & 10 & $27.9 \pm 2.8$ & $53.2 \pm 4.1$ \\
\hline BXD-27 & 18 & $20.4 \pm 1.8$ & $54.5 \pm 2.3$ & 9 & $21.3 \pm 1.9$ & $60 \pm 0$ & 9 & $19.5 \pm 3.3$ & $48.9 \pm 3.8$ \\
\hline BXD-28 & 18 & $18.3 \pm 1.3$ & $50.7 \pm 3.3$ & 9 & $17.4 \pm 1.7$ & $47.1 \pm 4.4$ & 9 & $19.2 \pm 1.9$ & $54.3 \pm 4.8$ \\
\hline BXD-29 & 19 & $17.9 \pm 1.3$ & $33.4 \pm 4.0$ & 9 & $16.9 \pm 1.9$ & $33.4 \pm 5.2$ & 10 & $18.8 \pm 1.8$ & $33.5 \pm 6.2$ \\
\hline BXD-30 & 14 & $18.9 \pm 1.1$ & $34.2 \pm 5.0$ & 7 & $18.0 \pm 1.6$ & $28.0 \pm 6.1$ & 7 & $19.9 \pm 1.6$ & $40.1 \pm 7.7$ \\
\hline BXD-31 & 16 & $13.0 \pm 1.1$ & $24.6 \pm 4.2$ & 7 & $12.6 \pm 1.3$ & $14.7 \pm 2.4$ & 9 & $13.3 \pm 1.7$ & $32.3 \pm 6.2$ \\
\hline BXD-32 & 21 & $13.6 \pm 1.2$ & $41.4 \pm 3.3$ & 10 & $12.4 \pm 1.3$ & $44.4 \pm 4.6$ & 11 & $14.7 \pm 2.0$ & $38.6 \pm 4.8$ \\
\hline
\end{tabular}

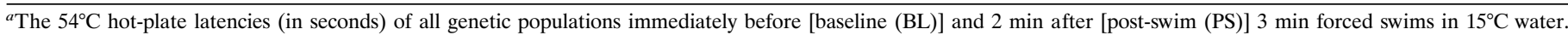

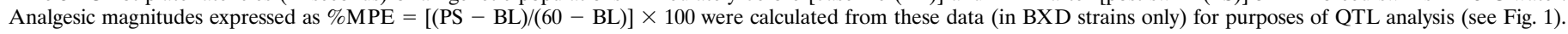

genotyping costs and effort by $>50 \%$, yet the power to detect QTLs is affected very little (Lander and Botstein, 1989).

Genomic DNA was isolated from spleen by a modification of the protein salting-out method (Miller et al., 1988), as described in Belknap et al. (1995). Microsatellites were amplified in 96-well microtiter plates using a modification of standard PCR procedures (Dietrich et al., 1992) with unlabeled commercially available marker primers (Research Genetics, Huntsville, AL). To each $200 \mathrm{ng}$ genomic DNA sample $(5 \mu \mathrm{l}), 20 \mu \mathrm{l}$ of PCR reactants was added (1 U Taq polymerase, $200 \mu \mathrm{M}$ dNTPs, 0.66 $\mu \mathrm{M}$ forward and reverse primers, $1-3 \mathrm{mM} \mathrm{MgCl}_{2}$ ). The mixture was subjected to the following PCR program: 3 min at $94^{\circ} \mathrm{C} ; 40$ cycles of $94^{\circ} \mathrm{C}$ for $1 \mathrm{~min}, 56^{\circ} \mathrm{C}$ for $2 \mathrm{~min}, 72^{\circ} \mathrm{C}$ for $3 \mathrm{~min} ; 7 \mathrm{~min}$ at $72^{\circ} \mathrm{C}$; indefinite hold at $4^{\circ} \mathrm{C}$. A $20 \%$ volume of bromophenol blue dye was added to PCR products, which were then separated by electrophoresis $(4 \mathrm{hr} / 10 \mathrm{~cm}$ at 70 $\mathrm{V})$ on high-resolution agarose gels (3\% Metaphor or NuSieve; FMC Bioproducts, Rockland, ME), stained with ethidium bromide $(1 \mu \mathrm{g} / \mathrm{ml})$, and visualized with ultraviolet light. A DNA ladder and samples from B6 and $\mathrm{D} 2$ progenitors were run concurrently, so that the relevant band in every gel lane (each corresponding to an individual $\mathrm{F}_{2}$ mouse) could be unequivocally assigned a genotype and an arbitrary gene dosage: homozygous B6 (0), homozygous D2 (1), or heterozygous (0.5).

Statistical analysis. BXD RI data were first subjected to two-way ANOVA (strain x sex). Correlation coefficients for each marker were calculated on the combined BXD RI data and on data from each sex separately. Because there are only two genotypic classes possible per marker in the BXD RI strains, the calculated $r$ value yields the same $p$ value as a one-way ANOVA or $t$ test between strains bearing each allele. For $F_{2}$ data, the MAPMAKER program (Lander et al., 1987) was used to construct a primary linkage map for the markers tested in each RI-implicated region (MAPMAKER/EXP) and to assess the presence of a QTL within this framework (MAPMAKER/QTL). The advantages of MAPMAKER include the use of interval mapping using maximum likelihood estimation to increase statistical power, and a built-in error checking routine. MAPMAKER is not presently amenable to RI data, so only $F_{2}$ data were analyzed in this way. $F_{2}$ data were subjected to MAPMAKER analysis only if the marker showing the highest correlation displayed $p<0.05$; otherwise the QTL was considered disconfirmed.

The two phases of this QTL mapping effort can be considered independent experiments testing the same hypothesis. As such, the $p$ values obtained for a given marker in the two experiments (BXD RI and $F_{2}$ ) were combined using the conservative method of Fisher (Sokal and Rohlf, 1981). To assess the significance of linkage, we used the stringent criteria recommended by Lander and colleagues (Lander and Schork, 1994; Lander and Kruglyak, 1995): RI, $p=0.00002$ [logarithm of the odds $(\mathrm{LOD})=3.9] ; \mathrm{F}_{2}(1 d f$; additive effects only), $p=0.0001(\mathrm{LOD}=$ 3.3). Because we are pooling results from these two types of experiments, we used the mean of the $\mathrm{RI}$ and $\mathrm{F}_{2} p$ value recommendations, or $p=$ $0.00006(\mathrm{LOD}=3.5)$. LOD scores were estimated from $p$ values on the basis of the asymptotic distribution of LOD as $\chi^{2}(d f=1)$ using the expression LOD $=1 / 2\left(\log _{10} \mathrm{e}\right) \chi^{2}$ for an additive $(d f=1$; no dominance $)$ model.

\section{RESULTS \\ BXD RI strain distribution}

Raw pre-swim and post-swim hot-plate latency data, for all mice combined and separately by sex, are presented in Table 1 . The baseline hot-plate sensitivity data have been analyzed and considered elsewhere (Mogil et al., 1997). Baseline nociceptive sensitivity and SIA magnitude were found to be significantly but modestly correlated $(r=0.26)$. The distribution of SIA magnitude in $\mathrm{B} 6, \mathrm{D} 2$, and $\left(\mathrm{B} 6 \mathrm{xD}_{2}\right) \mathrm{F}_{1}$ hybrids and BXD RI strains is shown in Figure 1. First, it is important to note that no significant differences were observed between the progenitor strains (B6 and 
Figure 1. $15^{\circ} \mathrm{C}$ swim SIA in $\mathrm{B} 6, \mathrm{D} 2$, and $(\mathrm{B} 6 \mathrm{xD} 2) \mathrm{F}_{1}$ hybrid and $24 \mathrm{BXD}$ RI strains. Mice were tested for nociceptive sensitivity on the $54^{\circ} \mathrm{C}$ hot-plate test immediately before and 2 min after a 3 min swim in $15^{\circ} \mathrm{C}$ water. Error bars represent mean \pm SEM percentage of the maximum possible effect (\%MPE) (see Materials and Methods) for all mice. Triangles represent mean of male mice only; circles represent mean of female mice only.

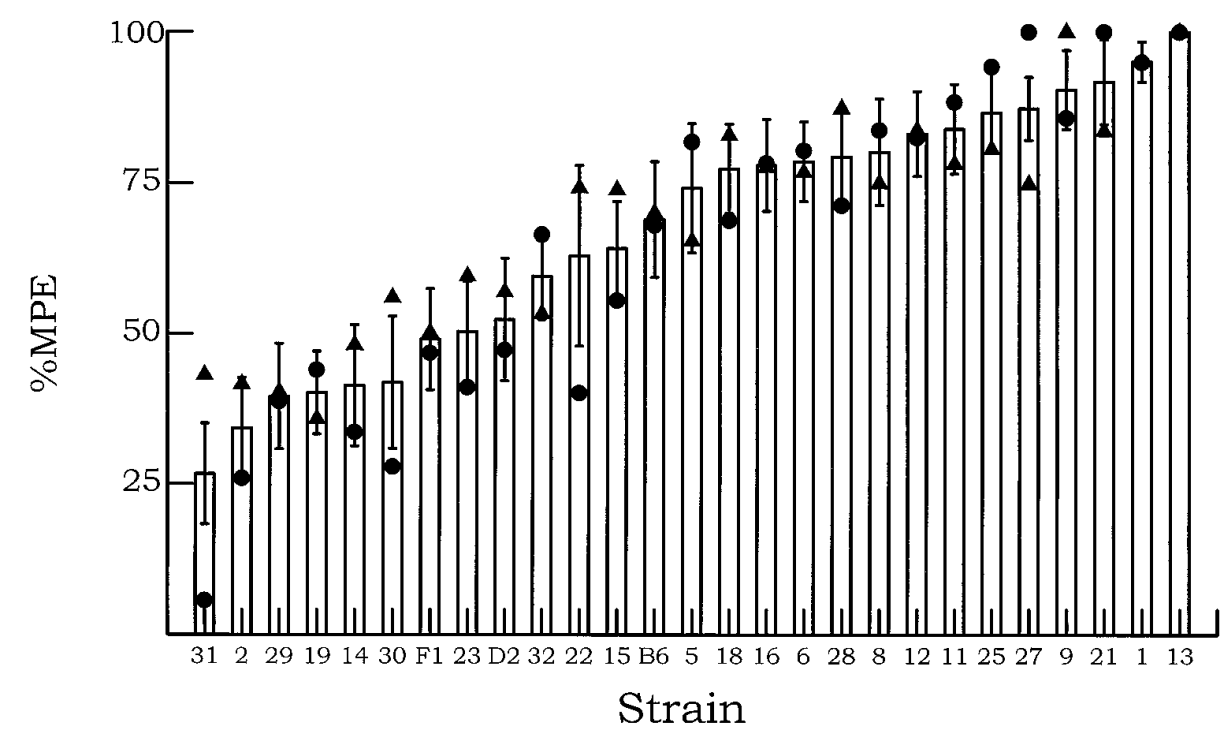

strains was not significantly different from normal, implying polygenic control of the phenotype in support of our previous contention (Mogil et al., 1992). Narrow sense heritability $\left(h^{2}\right)$ of this phenotype can be estimated by comparing the between-strain variance with the total variance and was found to be 0.32 in the RI set. This value implies that $32 \%$ of the total trait variance is attributable to genetic factors and is comparable to that of other behavioral traits to which QTL mapping has been applied successfully.

\section{BXD RI QTL analysis}

The QTL analysis of SIA magnitude in BXD RI strains is shown in Table 2. Six chromosomal regions were found to be associated with SIA magnitude at $p<0.01$ (uncorrected) when data from both sexes were combined. A reanalysis of this data set by sex revealed disparities in the apparent strength of the correlation in males versus females in one of these QTL regions, the D8Rik78 region of chromosome 8 (Table 3). None of these QTL regions were similar to those identified previously for baseline hot-plate nociception (Mogil et al., 1997) or morphine analgesia (Belknap and Crabbe, 1992; Belknap et al., 1995).

\section{(B6xD2)F 2 QTL confirmation}

As described in Materials and Methods, all six regions implicated from the BXD RI data at the $p<0.01$ level were subjected to confirmation using $\mathrm{F}_{2}$ hybrids of both sexes and at least four quent one-way ANOVA revealed a significant effect of strain $\left(F_{23,356}=7.43 ; p<0.001\right)$. The frequency distribution of these

\begin{tabular}{|c|c|c|c|}
\hline Marker & Location & $r$ & Present status \\
\hline Ms15-6 & Chromosome $5 ; 42 \mathrm{cM}$ & $-0.618 * *$ & Disconfirmed \\
\hline Brp1 & Chromosome $6 ; 32 \mathrm{cM}$ & $0.559^{*}$ & Putative $^{b}$ \\
\hline D8Rik78 & Chromosome $8 ; 55-56 \mathrm{cM}$ & $0.643^{* * *}$ & Confirmed for females only ${ }^{b}$ \\
\hline D11Ncvs69 & Chromosome 11; $16 \mathrm{cM}$ & $-0.575^{* *}$ & Disconfirmed \\
\hline Cbg & Chromosome 12; $51 \mathrm{cM}$ & $0.524 *$ & Disconfirmed \\
\hline D17Mit22 & Chromosome 17; $10 \mathrm{cM}$ & $0.630 * *$ & Disconfirmed \\
\hline
\end{tabular}

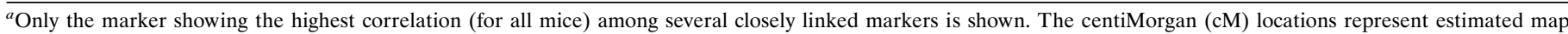

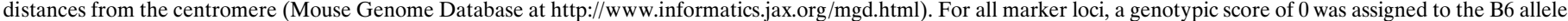

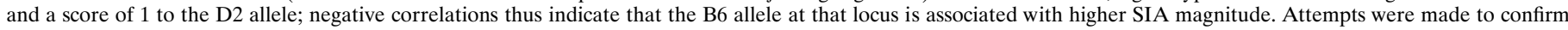
all six QTL regions in a $(\mathrm{B} 6 \mathrm{xD} 2) \mathrm{F}_{2}$ hybrid population; four of these attempts were unsuccessful, indicating that the loci were likely false positives.

${ }^{b}$ See Table 3 for details.

${ }^{*} p<0.01 ;{ }^{* *} p<0.005 ; * * * p<0.0001$. 
Table 3. Statistical analysis of two putative QTLs for $15^{\circ} \mathrm{C}$ swim SIA

\begin{tabular}{|c|c|c|c|c|c|c|c|c|}
\hline \multirow[b]{2}{*}{ QTL } & \multirow[b]{2}{*}{ Sex } & \multicolumn{3}{|c|}{ BXD experiment $^{a}$} & \multicolumn{2}{|c|}{$\mathrm{F}_{2}$ hybrid experiment ${ }^{b}$} & \multicolumn{2}{|c|}{ Combined data $^{c}$} \\
\hline & & $r$ & $p$ & LOD & $p$ & LOD & $p$ & LOD \\
\hline \multirow[t]{2}{*}{8} & $\mathrm{~F}$ & 0.732 & $4.8 \times 10^{-5}$ & 3.6 & $1.6 \times 10^{-4}$ & 3.1 & $1.2 \times 10^{-7}$ & $6.1^{*}$ \\
\hline & M & 0.452 & 0.026 & 1.1 & 0.274 & 0.3 & 0.038 & 0.9 \\
\hline 6 & $F+M$ & 0.559 & 0.0084 & 1.5 & 0.019 & 2.0 & 0.002 & 2.1 \\
\hline
\end{tabular}

${ }^{a}$ Calculated at marker showing peak correlation among several closely linked markers.

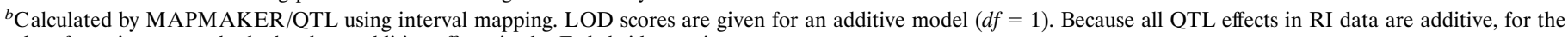
sake of consistency we looked only at additive effects in the $F_{2}$ hybrid experiment.

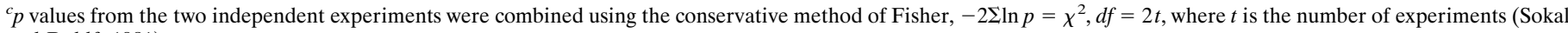
and Rohlf, 1981).

*This value far exceeds criterion levels of significance proposed by Lander and Kruglyak (1995).

markers bracketing the QTL region (including one marker mapping within $1 \mathrm{cM}$ of the location showing the highest statistical association). Four of the six putative QTL regions were disconfirmed, that is, found to be apparent false positives, indicated by a lack of $p<0.05$ correlation at any marker in the region (data not shown). The present finding of four of six false positives obtained from a BXD RI QTL screen is only slightly higher than predicted by our computer simulations (i.e., half false positives) (Belknap et al., 1996). It remains possible, of course, that these regions truly are associated with $15^{\circ} \mathrm{C}$ swim SIA and that we simply lack the statistical power to demonstrate their linkage with the limited number of $\mathrm{F}_{2}$ mice used presently. This is especially likely for QTLs with small effects on the trait.

In one of the remaining QTL regions, the Ms6-4 to D6Rik58 region of chromosome $6(30-39 \mathrm{cM})$, we obtained some further evidence supporting the existence of a QTL using $F_{2}$ mice, although the overall LOD score so far obtained $(\mathrm{LOD}=2.1$ ) (Table 3) is not significant. This LOD score may yet reach statistical significance once the sample size is increased, and efforts are currently underway to do so. We have an independent reason to believe that this region is a true QTL: Tarricone and colleagues (1995) have identified this same region as a QTL for hyperlocomotion after restraint stress. In contrast, strong evidence was obtained, even with the limited number of $F_{2}$ mice tested, showing that the QTL region on chromosome 8 is significantly associated with $15^{\circ} \mathrm{C}$ swim SIA. In addition, an unequivocal sex-specificity was observed in the $\mathrm{F}_{2}$ data. The combined BXD RI and $\mathrm{F}_{2}$ hybrid significance levels $(p=0.00000012$;
LOD $=6.1$ ) far exceed the criterion values for significant linkage proposed by Lander and Kruglyak (1995) for female mice alone. By contrast, combined BXD RI and $\mathrm{F}_{2}$ hybrid significance levels for male mice alone $(p=0.038$; LOD $=0.9)$ show no evidence of the existence of a QTL (Table 3). The difference in $p$ values between the two sexes was significant ( $p<0.01$; diff use test) (Woolf, 1986). We thus propose that this QTL be named Fsia1, because it seems to mediate SIA in female mice only. This QTL has large effects, accounting for between 53.5 and $82.2 \%$ of the genetic variance and between 17.1 and $26.3 \%$ of the total trait variance in female mice of these strains (estimated from BXD RI data and $\mathrm{F}_{2}$ data, respectively). The location of the QTL within a $95 \%$ confidence interval (CI) as estimated by MAPMAKER/QTL (using a 1 LOD drop-off) is somewhere within $52 \mathrm{cM}$ of the centromere and the distal end of the chromosome $(84 \mathrm{cM})$. A $95 \%$ CI of similar size is estimated by the formula of Darvasi and Soller (1997): CI $=(530 /[n \cdot \nu])=39 \mathrm{cM}$, where $\nu=$ proportion of trait variance explained by the QTL. The resolving power to localize this QTL can be improved markedly by increasing the sample size (Darvasi and Soller, 1997), and this effort is underway in the laboratory of the first author. As can be seen in Figure 2, female mice possessing homozygous D2 alleles at markers located in this region of chromosome 8 exhibit SIA magnitudes approximately double those of female mice possessing homozygous B6 alleles. In contrast, inheritance of D2 alleles at these markers confers no increase in SIA magnitudes in male mice.

\section{D8Mit215 (59 cM)}

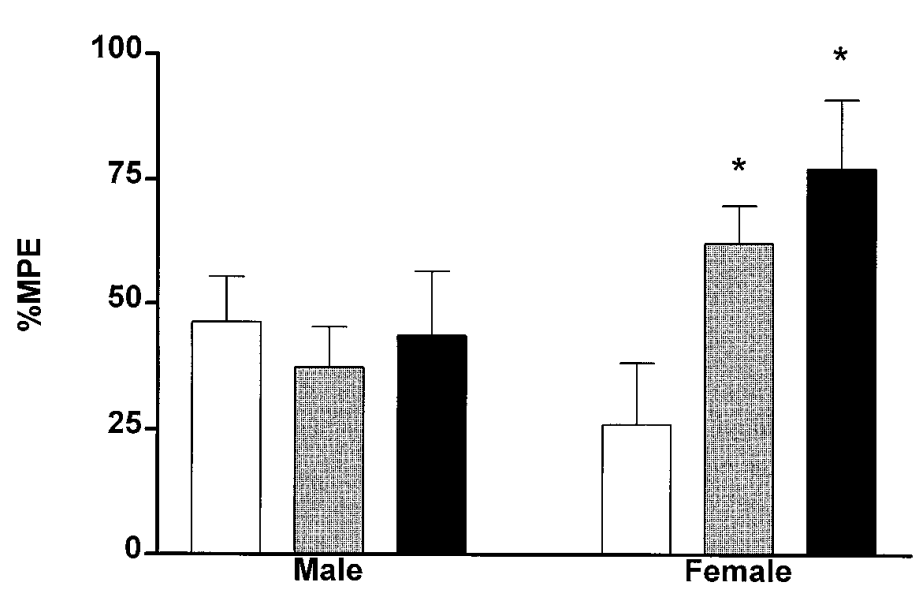

Figure 2. $\quad 15^{\circ} \mathrm{C}$ swim SIA (measured in \% MPE) in male and female $\left(\mathrm{B} 6 \mathrm{xD}_{2}\right) \mathrm{F}_{2}$ hybrid mice homozygous for the B6 allele (B6/B6), heterozygous (B6/D2), or homozygous for the D2 allele (D2/D2) of the microsatellite marker D8Mit215, located $\sim 59 \mathrm{cM}$ from the centromere on mouse chromosome 8 . Inheritance of either allele is irrelevant to SIA magnitude in male $\mathrm{F}_{2}$ mice. In contrast, inheritance of the D2 allele confers significantly greater SIA in female $\mathrm{F}_{2}$ mice. $\mathrm{Fe}$ male $\mathrm{D} 2 / \mathrm{D} 2$ mice remain on the $54^{\circ} \mathrm{C}$ hot plate $20 \mathrm{sec}$ longer than female B6/B6 mice. These data strongly suggest that a gene responsible for the majority of genetic variance in this trait in females is located in the vicinity of D8Mit 215 . Two-way ANOVA revealed a significant gene dosage $\times$ sex interaction $\left(F_{2,122}=3.44 ; p=\right.$ 0.038). A subsequent one-way ANOVA in female mice revealed a significant simple main effect of gene dosage $\left(F_{2,51}=4.60 ; p<0.015\right)$. ${ }^{*} p<0.05$ versus B6/B6 by Tukey's post hoc test. 


\section{DISCUSSION}

The present study identifies a large QTL associated with variability in swim SIA in mice, which we name Fsial for female-specific SIA, because the QTL is significantly associated with variability in this trait in female but not male mice. This QTL is located at the distal portion of mouse chromosome 8 , in a region showing syntenic conservation with human chromosomal region 16q22. The existence of female-specific QTLs was predicted by our demonstration several years ago that female mice possess a sexspecific SIA mechanism (Mogil et al., 1993). These data provide direct support for the growing appreciation that genetic background and sex are important influences on pain and pain inhibition.

\section{Candidate genes and future directions}

It is important to realize that QTL mapping efforts such as the present one do not identify the genes underlying the mapped traits; they identify only the approximate genomic locations of such genes. The microsatellites found to be statistically associated with SIA variance in female mice on chromosome 8 are typically noncoding stretches of DNA likely to have no effect on the trait in question. These microsatellites merely serve as markers. Because they are genetically linked (and thus cosegregate) with the genes that are trait-relevant, they are useful for localizing such genes; however, the $>30 \mathrm{cM}$ region representing the $95 \% \mathrm{CI}$ containing the gene(s) representing the QTL contains hundreds or even thousands of genes, most of which remain unknown at the present time. We have had considerable success in the recent past identifying candidate genes residing in the QTL region for morphine analgesia (Oprm: encoding the $\mu$-opioid receptor; Htrlb: encoding the serotonin 5- $\mathrm{HT}_{1 \mathrm{~B}}$ receptor) (Belknap et al., 1995; Mogil et al., 1995) and basal sensitivity to thermal nociception (Oprd1: encoding the $\delta$-opioid receptor) (Mogil et al., 1997). In each case we were able to provide pharmacological evidence supporting the contention that the candidate gene truly represented the QTL. For instance, the whole-brain homogenate $B_{\max }$ (receptor density) for naloxone, using concentrations expected to be largely $\mu$ specific, was found also to map to the same chromosomal region (chromosome 10; 0-10 cM) as Oprm and the QTL for morphine analgesia. With respect to $H t r l b$, we have observed a correlation between analgesic sensitivity to morphine and to the serotonin-1B agonist CGS 12066 and greatly altered morphine dose-response relationships in transgenic knock-out mice lacking functional expression of this gene (Mogil et al., 1995).

In the present study, however, we can find no candidate genes of obvious relevance to swim SIA in this region. A few genes of possible relevance include $Z f p 1$ and $Z f p 4$, which encode zinc finger proteins that also act as transcriptional activators (chromosome $8 ; 54-55 \mathrm{cM}$ ), and Tat, which encodes tyrosine aminotransferase, a metabolic enzyme for tyrosine that is induced by stress via activation of the glucocorticoid receptor (chromosome 8; 55 cM) (Alexandrova, 1994). Formal genetic confirmation of a candidate gene for a QTL requires the study of additional strains, fine-structure mapping to test whether the candidate gene and the QTL are recombinationally inseparable, and ultimately, allelic substitution for the candidate gene in transgenic mice.

It is likely that the gene (or genes) truly representing Fsial have not yet been cloned and mapped. A number of strategies exist to directly identify genes, including positional cloning (i.e., highresolution mapping) and subtractive hybridization (e.g., genetically directed representational difference analysis) (Crabbe et al., 1994). The first step toward either of these ends would likely be the use of classic genetic approaches to transfer the gene of interest from a donor strain (D2) onto a background strain (B6). The resultant congenic lines would be genetically identical except for a small region surrounding the target gene, serving as a confirmation of the role of the QTL in the trait and permitting further localization of the gene. We have previously constructed such congenic lines for the region of chromosome 9 surrounding the $H$ tr $1 \mathrm{~b} / \mathrm{d}$ locus that we have implicated in morphine analgesic sensitivity, and these lines exhibit altered analgesic responses compared with wild-type littermates (H. Hain, J. S. Mogil, and J. K. Belknap, unpublished observations).

\section{Sex-specific QTLs}

To our knowledge, this is only the fourth demonstration of a sex-specific QTL residing on an autosome. Melo and colleagues (1996) recently reported the identification of a male-specific (Alcp1) and a female-specific (Alcp2) QTL associated with alcohol preference in the mouse, another trait with well documented sex differences. In their study, which used backcrosses between the ethanol-preferring B6 mouse and the ethanol-avoiding D2 mouse, parent-of-origin effects were observed for Alcp2, which the authors explained in terms of genomic imprinting. We did not keep track of the grandparental strains of the segregating $\mathrm{F}_{2}$ mice used for the QTL analysis, so we cannot presently evaluate either genomic imprinting or the possible existence of an X-linked locus with complementary activity to Fsia1. Clark and colleagues (1996) recently identified two QTLs associated with hypertension in male rats only, using an $\mathrm{F}_{2}$ cross between the normotensive Wistar-Kyoto rat and the stroke-prone spontaneously hypertensive rat.

We recently reported the possible existence of a male-specific QTL associated with basal sensitivity to acute, thermal nociception as measured on the hot-plate assay (Mogil et al., 1997). B6 and D2 mice are known to display divergent baseline hot-plate latencies (D2 > B6, implying that B6 mice are more sensitive to this type of nociception), and a QTL analysis of the baseline data presented in Table 1 revealed a QTL on chromosome 4 that was significantly associated with hot-plate latency in male but not female mice.

In that study a viable candidate gene was identified: the Oprd1 gene that encodes the murine $\delta$-opioid receptor. Supporting the potential role of Oprd1 in the mediation of thermal nociceptive sensitivity, we found that the $\delta$-receptor antagonist naltrindole and the $\delta_{2}$ antagonist naltriben (but not the $\delta_{1}$ antagonist 7benzylidenenaltrexone, lowered baseline hot-plate latencies in a strain- and sex-dependent manner predicted by the mapping data: D2 male $>$ B6 male $>$ D2 female $>$ B6 female. In female mice of both strains, neither naltrindole nor naltriben produced significant alterations in nociceptive sensitivity.

\section{Sex-specific mechanisms of swim SIA}

It is now widely appreciated that important sex differences exist in pain sensitivity and sensitivity to analgesics in humans, even when sociocultural factors are accounted for pimprivate (for review, see Fillingim and Maixner, 1995; Unruh, 1996; Berkley, 1997). In general, when differences are found, females of many species are more sensitive to and less tolerant of pain than are males, and also less sensitive to opioid and nonopioid analgesic manipulations pimprivate (Lipsitt and Levy, 1959; Beatty and Beatty, 1970; Bodnar et al., 1988; Feine et al., 1991; Kepler et al., 1991; Kiefel and Bodnar, 1991; Kavaliers and Innes, 1992; Aloisi et al., 1994; Menendez et al., 1994; Cicero et al., 1996; but see Gear et al., 1996). 
We (Mogil et al., 1993) and others (Wong, 1987; Romero et al., 1988) have also observed qualitative sex differences in the mediation of opioid and nonopioid pain inhibition, implying differential neurochemical mediation of similar phenomena in each sex. We demonstrated that the naloxone-insensitive SIA displayed by Swiss-Webster mice after 3 min swims in $15^{\circ} \mathrm{C}$ water was significantly attenuated by a low dose of dizocilpine (MK-801, 0.075 $\mathrm{mg} / \mathrm{kg}$ ) in males but not females (Mogil et al., 1993). Thus, the nonopioid SIA produced by these swim parameters was NMDAergic in male mice only. The fact that the SIA was equipotent in both sexes but undiminished in females treated with naloxone and dizocilpine led us to propose the existence of a female-specific SIA mechanism. In this same study we demonstrated that ovariectomy unmasked the "male" pattern of dizocilpine antagonism, and that expression of the "female" system was reinstated in these animals by estrogen replacement (Mogil et al., 1993). We have determined that intact female mice remain dizocilpine-insensitive throughout their estrous cycle (Sternberg et al., 1994). This novel, female-specific, nonopioid swim SIA mechanism has subsequently been found to be dependent for its expression on the absence of testosterone during ontogeny (Sternberg et al., 1996), to be expressed only after puberty but to persist after estropause (W. F. Sternberg, unpublished observations), and to vary with circannual reproductive status such that it is expressed only in female deer mice (Peromyscus maniculatus) maintained in a photoperiod-induced state of cyclicity (Kavaliers and Galea, 1996). Intriguingly, it has also been reported that female mice have much lower dizocilpine binding in the forebrain after acute swim stress than do males (Akinci and Johnston, 1993) and that estradiol can regulate NMDA binding in the rat hippocampus (Weiland, 1992). Very recently, Kavaliers and Choleris (1997) have reported that exposure to predator (weasel) odor produces SIA that is completely reversed by the competitive NMDA antagonist NPC 12626 in male mice, whereas it produces equipotent SIA in female mice that is completely unaffected by such antagonism. In the same study these authors show that the analgesic effects of the $\kappa$-opioid agonist U69,593 display the same sexually dimorphic pattern of antagonism. These data are important because they show that this phenomenon is not specific to dizocilpine, swim stress, or even SIA, but rather that the femalespecific analgesic mechanism may have broad relevance.

The present data are unsatisfying in that they provide no direct insight into the neurochemical basis of SIA in either male or female mice. This problem is likely to be temporary for two reasons: (1) the phenotyping and genotyping of additional $F_{2}$ mice, and of congenic mice, will increase statistical power to further localize the QTL on chromosome 8 and the putative QTL on chromosome 6 , and (2) neurochemically relevant genes that reside in these regions will be identified by others, providing candidate genes for these QTLs in the future. Although the exact nature of Fsial remains elusive at the present time, its discovery provides additional and compelling evidence for the existence of female-specific mechanisms of nociceptive modulation in the rodent. Should such sexually dimorphic pain-modulatory systems be shown to exist in humans as well, it would not be unduly speculative to propose that qualitatively different analgesic strategies may one day be applied to each sex.

\section{REFERENCES}

Akinci MK, Johnston GAR (1993) Sex differences in acute swim stressinduced changes in the binding of MK-801 to the NMDA subclass of glutamate receptors in mouse forebrain. J Neurochem 61:2290-2293.
Alexandrova M (1994) Stress induced tyrosine aminotransferase activity via glucocorticoid receptor. Horm Metab Res 26:97-99.

Aloisi AM, Albonetti ME, Carli G (1994) Sex differences in the behavioural response to persistent pain in rats. Neurosci Lett 179:79-82.

Basbaum AI, Fields HL (1984) Endogenous pain control systems: brainstem spinal pathways and endorphin circuitry. Annu Rev Neurosci 7:309-338.

Beatty WW, Beatty PA (1970) Hormonal determinants of sex differences in avoidance behavior and reactivity to electric shock in the rat. J Comp Physiol Psychol 16:413-417.

Belknap JK, Crabbe JC (1992) Chromosome mapping of gene loci affecting morphine and amphetamine responses in BXD recombinant inbred mice. Ann NY Acad Sci 654:311-323.

Belknap JK, O'Toole LA (1991) Studies of genetic differences in response to opioid drugs. In: The genetic basis of alcohol and drug actions (Harris RA, Crabbe JC, eds), pp 225-252. New York: Plenum.

Belknap JK, Mogil JS, Helms ML, Richards SP, O’Toole LA, Bergeson SE, Buck KJ (1995) Localization to proximal chromosome 10 of a locus influencing morphine-induced analgesia in crosses derived from C57BL/6 and DBA/2 mouse strains. Life Sci 57:PL117-124.

Belknap JK, Mitchell SR, O'Toole LA, Helms ML, Crabbe JC (1996) Type I and Type II error rates for quantitative trait loci (QTL) mapping studies using recombinant inbred mouse strains. Behav Genet 26:149-160.

Ben-Eliyahu S, Page GG, Marek P, Kest B, Taylor AN, Liebeskind JC (1993) The NMDA receptor antagonist MK-801 blocks non-opioid stress induced analgesia and decreases tumor metastasis in the rat. Proc West Pharmacol Soc 36:293-298.

Berkley KJ (1997) Sex differences in pain. Behav Brain Sci, in press.

Bodnar RJ, Merrigan KP, Sperber ES (1983) Potentiation of cold-water swim analgesia and hypothermia by clonidine. Pharmacol Biochem Behav 19:447-451.

Bodnar RJ, Romero M-T, Kramer E (1988) Organismic variables and pain inhibition: roles of gender and aging. Brain Res Bull 21:947-953.

Cannon JT, Prieto GJ, Lee A, Liebeskind JC (1982) Evidence for opioid and non-opioid forms of stimulation-produced analgesia in the rat. Brain Res 243:315-321.

Carmody JJ (1995) Avoiding fallacies in nociceptive measurements. Pain 63:136.

Chance WT (1986) The role of brain and spinal cord norepinephrine in autoanalgesia. Ann NY Acad Sci 467:309-330.

Cicero TJ, Nock B, Meyer ER (1996) Gender-related differences in the antinociceptive properties of morphine. J Pharmacol Exp Ther 279:767-773.

Clark JS, Jeffs B, Davidson AO, Lee WK, Anderson NH, Bihoreau M-T, Brosnan MJ, Devlin AM, Kelman AW, Lindpaintner K, Dominiczak AF (1996) Quantitative trait loci in genetically hypertensive rats: possible sex specificity. Hypertension 28:898-906.

Coderre TJ, Rollman GB (1984) Stress analgesia: effects of PCPA, yohimbine, and naloxone. Pharmacol Biochem Behav 21:681-686.

Crabbe JC, Belknap JK, Buck KJ (1994) Genetic animal models of alcohol and drug abuse. Science 264:1715-1723.

Darvasi A, Soller M (1997) A simple method to calculate resolving power and confidence interval of QTL map location. Behav Genet 27:125-132.

Dietrich W, Katz H, Lincoln SE, Shin H-S, Friedman J, Dracopoli NC, Lander ES (1992) A genetic map of the mouse suitable for typing intraspecific crosses. Genetics 131:423-427.

Dietrich WF, Miller J, Steen R, Merchant MA, Damron-Boles D, Husain Z, Dredge R, Daly MJ, Ingalls KA, O'Connor TJ, Evans CA, DeAngelis MM, Levinson DM, Kruglyak L, Goodman N, Copeland NG, Jenkins NA, Hawkins TL, Stein L, Page DC, Lander ES (1996) A comprehensive genetic map of the mouse genome. Nature 380:149-152.

Feine JS, Bushnell MC, Miron D, Duncan GH (1991) Sex differences in the perception of noxious heat stimuli. Pain 44:255-262.

Fillingim RB, Maixner W (1995) Gender differences in the responses to noxious stimuli. Pain Forum 4:209-221.

Gear RW, Miaskowski C, Gordon NC, Paul SM, Heller PH, Levine JD (1996) Kappa-opioids produce significantly greater analgesia in women than in men. Nature Med 2:1248-1250.

Gogas KR, Hough LB (1989) Inhibition of naloxone-resistant antinociception by centrally administered $\mathrm{H}_{2}$-antagonists. J Pharmacol Exp Ther 248:262-267.

Gogas KR, Hough LB, Glickl SD, Su K (1986) Opposing actions of 
cimetidine on naloxone-sensitive and naloxone-insensitive forms of footshock-induced analgesia. Brain Res 370:370-374.

Gora-Maslak G, McClearn GE, Crabbe JC, Phillips TJ, Belknap JK, Plomin R (1991) Use of recombinant inbred strains to identify quantitative trait loci in psychopharmacology. Psychopharmacology 104:413-424.

Kavaliers M (1988) Brief exposure to a natural predator, the short-tailed weasel, induces benzodiazepine-sensitive analgesia in white-footed mice. Physiol Behav 43:187-193.

Kavaliers M, Choleris E (1997) Sex differences in NMDA involvement in kappa opioid and non-opioid predator-induced analgesia in mice. Brain Res, in press.

Kavaliers M, Colwell DD (1991) Sex differences in opioid and nonopioid mediated predator-induced analgesia in mice. Brain Res 568:173-177.

Kavaliers M, Galea LAM (1996) Sex differences in the expression and antagonism of swim stress-induced analgesia in deer mice vary with the breeding season. Pain 63:327-334.

Kavaliers M, Hirst M (1983) Daily rhythms of analgesia in mice: effects of age and photoperiod. Brain Res 279:387-393.

Kavaliers M, Innes DGL (1992) Sex differences in the effects of neuropeptide FF and IgG from neuropeptide FF on morphine- and stressinduced analgesia. Peptides 13:603-607.

Kelly DD (ed) (1986) Stress-induced analgesia. Ann NY Acad Sci 467.

Kepler KL, Standifer KM, Paul D, Kest B, Pasternak GW, Bodnar RJ (1991) Gender effects and central opioid analgesia. Pain 45:87-94.

Kiefel JM, Bodnar RJ (1991) Roles of gender and gonadectomy in pilocarpine and clonidine analgesia in rats. Pharmacol Biochem Behav 41:153-158.

Lander ES, Botstein D (1989) Mapping Mendelian factors underlying quantitative traits using RFLP linkage maps. Genetics 121:185-199.

Lander ES, Kruglyak L (1995) Genetic dissection of complex traits: guidelines for interpreting and reporting linkage results. Nat Genet 11:241-247.

Lander ES, Schork NJ (1994) Genetic dissection of complex traits. Science 265:2037-2048.

Lander ES, Green P, Abrahamson J, Barlow A, Daly MJ, Lincoln SE, Newburg L (1987) MAPMAKER: an interactive computer package for constructing primary genetic linkage maps of experimental and natural populations. Genomics 1:174-171.

Lewis JW, Cannon JT, Liebeskind JC (1980) Opioid and non-opioid mechanisms of stress analgesia. Science 208:623-625.

Lipsitt LP, Levy N (1959) Electrotactual threshold in the neonate. Child Dev 30:547-554.

Manly KE (1993) A Macintosh program for storage and analysis of experimental genetic mapping data. Mamm Genome 4:303-313.

Marek P, Page GG, Ben-Eliyahu S, Liebeskind JC (1991) NMDA receptor antagonist MK-801 blocks non-opioid stress-induced analgesia. I. Comparison of opiate receptor-deficient and opiate receptor-rich strains of mice. Brain Res 551:293-296.

Marek P, Mogil JS, Sternberg WF, Panocka I, Liebeskind JC (1992)Nmethyl-D-aspartic acid (NMDA) receptor antagonist MK-801 blocks non-opioid stress-induced analgesia. II. Comparison across three swim stress paradigms in selectively bred mice. Brain Res 578:197-203.

Mayer DJ, Frenk H (1988) The role of neuropeptides in pain. In: Neuropeptides in psychiatric and neurological disorders (Nemeroff CB, ed), pp 199-280. Baltimore: Johns Hopkins UP.

Melo JA, Shendure J, Pociask K, Silver LM (1996) Identification of sex-specific quantitative trait loci controlling alcohol preference in C57BL/6 mice. Nat Genet 13:147-153.

Menendez L, Andres-Trelles F, Hidalgo A, Baamonde A (1994) Gender and test dependence of a type of kappa mediated stress-induced analgesia in mice. Gen Pharmacol 25:903-908.

Miller SA, Dykes DD, Polesky HF (1988) A simple salting out procedure for extracting DNA from human nucleated cells. Nucleic Acids Res 16:1215.

Mogil JS, Belknap JK (1997) Sex and genotype determine the selective activation of neurochemically-distinct mechanisms of swim stressinduced analgesia. Pharmacol Biochem Behav 56:61-66.
Mogil JS, Marek P, Sternberg WF, Spence MA, Liebeskind JC (1992) A genetic analysis of swim stress-induced analgesia in selectively bred mice. Soc Neurosci Abstr 18:686.

Mogil JS, Sternberg WF, Kest B, Marek P, Liebeskind JC (1993) Sex differences in the antagonism of swim stress-induced analgesia: effects of gonadectomy and estrogen replacement. Pain 253:17-25.

Mogil JS, Sadowski B, Belknap JK (1995) The role of the serotonin-1B receptor in genetic sensitivity to opiate analgesia in mice. Soc Neurosci Abstr 21:1415.

Mogil JS, Kest B, Sadowski B, Belknap JK (1996a) Differential genetic mediation of sensitivity to morphine in genetic models of opiate antinociception: influence of nociceptive assay. J Pharmacol Exp Ther 276:532-544.

Mogil JS, Sternberg WF, Balian H, Liebeskind JC, Sadowski B (1996b) Opioid and non-opioid swim stress-induced analgesia: a parametric analysis in mice. Physiol Behav 59:123-132.

Mogil JS, Sternberg WF, Marek P, Sadowski B, Belknap JK, Liebeskind JC (1996c)

The genetics of pain and pain inhibition. Proc Natl Acad Sci USA 93:3048-3055.

Mogil JS, Richards SP, O’Toole LA, Helms ML, Mitchell SR, Belknap JK (1997) Genetic sensitivity to hot-plate nociception in DBA/2J and C57BL/6J inbred mouse strains: possible sex-specific mediation by $\delta_{2}$-opioid receptors. Pain 70:267-277.

Rodgers RJ, Randall JI (1987) Benzodiazepine ligands, nociception and "defeat" analgesia in male mice. Psychopharmacology 91:305-315.

Rodgers RJ, Shepherd JK (1989) Prevention of the analgesic consequences of social defeat in male mice by $5-\mathrm{HT}_{1 \mathrm{~A}}$ anxiolytics, buspirone, gepirone and ipsapirone. Psychopharmacology 99:374-380.

Rodgers RJ, Shepherd JK, Randall JI (1990) Highly potent inhibitory effects of 5-HT3 receptor antagonist, GR38032F, on non-opioid defeat analgesia in male mice. Neuropharmacology 29:17-23.

Romero M-T, Kepler KL, Bodnar RJ (1988) Gender determinants of opioid mediation of swim analgesia in rats. Pharmacol Biochem Behav 29:705-709.

Sokal RR, Rohlf FJ (1981) Biometry. San Francisco: Freeman.

Sternberg WF, Mogil JS, Pilati ML, Boun C, Wong SK, Liebeskind JC (1994) Neurochemical quality of nonopioid stress-induced analgesia is not altered by estrous phase in female mice. Proc West Pharmacol Soc 37:141-143.

Sternberg WF, Mogil JS, Kest B, Page GG, Leong Y, Yam V, Liebeskind JC (1996) Neonatal testosterone exposure influences neurochemistry of swim stress-induced analgesia in adult mice. Pain 63:321-326.

Tarricone BJ, Hingtgen JN, Belknap JK, Mitchell SR, Nurnberger J (1995) Quantitative trait loci associated with the behavioral response of BXD recombinant inbred mice to restraint stress: a preliminary communication. Behav Genet 25:489-495.

Terman GW, Shavit Y, Lewis JW, Cannon JT, Liebeskind JC (1984) Intrinsic mechanisms of pain inhibition: activation by stress. Science 226:1270-1277.

Tierney G, Carmody JJ, Jamieson D (1991) Stress analgesia: the opioid analgesia of long swims suppresses the non-opioid analgesia induced by short swims in mice. Pain 46:89-95.

Unruh AM (1996) Gender variations in clinical pain experience. Pain 65:123-167.

Watkins LR, Mayer DJ (1982) The organization of endogenous opiate and nonopiate pain control system. Science 216:1185-1192.

Watkins LR, Wiertelak EP, Grisel JE, Silbert LH, Maier SF (1992) Parallel activation of multiple spinal opiate systems appears to mediate "non-opiate" stress-induced analgesias. Brain Res 594:99-108.

Weiland NG (1992) Estradiol selectively regulates agonist binding sites on the $N$-methyl-D-aspartate receptor complex in the $\mathrm{CA}_{1}$ region of the hippocampus. Endocrinology 131:662-668.

Wong C-L (1987) Sex difference in naloxone antagonism of swim stress induced antinociception in mice. Methods Find Exp Clin Pharmacol 9:275-278.

Woolf FM (1986) Meta-analysis: quantitative methods for research synthesis. Beverly Hills, CA: Sage Publications. 